\title{
Students' Difficulties in Solving Ratios and Proportional Relationships Problems
}

\author{
Nabila Ismi Fauziah ${ }^{1}$, Endang Cahya M.A. ${ }^{2}$ \\ \{nabilaismi12@student.upi.edu ${ }^{1}$, endangcahya@gmail.com² ${ }^{2}$, \\ Universitas Pendidikan Indonesia, Dr. Setiabudi No. 229, Bandung 40154, Indonesia ${ }^{12}$
}

\begin{abstract}
This study aims to describe students' difficulties in solving ratios and proportional relationships problems. Qualitative research using the described method was the methods of this research which cover three stages. First, we developed four problems on ratios and proportional relationships. Second, we tested the problem with ten students in Grade 8th (15-16 years old) and interviewed all students about their solutions to the problem. Finally, we analyzed student answer papers and the results of the interviews that had been conducted. The results showed that are three common types of students' difficulties in solving ratios and proportional relationships problems: (1) difficulty in ratios and proportional relationships word problems, (2) difficulty in applying arithmetic operations, and (3) difficulty in understanding the concept of ratios and proportional relationships.
\end{abstract}

Keywords: Students' Difficulties, Ratios and Proportional Relationships.

\section{Introduction}

Mathematics is necessary knowledge and very important for all students. One of the mathematical concepts often applied in everyday life is ratios and proportional relationships [1]. The Common Core State Standards for Mathematics (CCSSM) consider ratios and proportional relationships topics as one of the curriculum's five critical areas in grades 6th and 7th [2]. The concepts of ratios and proportional relationships are prerequisite materials for mathematical concepts at a higher level. Even the concepts of ratios and proportional relationships are often used in many other concepts beyond mathematics [3-6]. Therefore, students had to master the concepts of ratios and proportional relationships as a bridge to mastering advanced mathematics.

Despite the concept of ratios and proportional relationships being essential, Indonesian students' learning outcomes on this concept show the opposite result. Based on the results of Trend in International Mathematics and Science Study (TIMSS) 2011, the overall average of Indonesian students who correctly answered TIMSS 2011 questions in the domain of content was 24 percent, while the average of international students was 43 percent [7]. It shows that the Indonesian students have difficulties in the number content domain, including ratios and proportional relationships.

The National Examination Report conducted by the Indonesian government in 2018, show that students' performance in solving ratios and proportional relationships problems in West Java Indonesia, especially in Bandung district, is still low; worth 39.50 lower than the average national exam results throughout Indonesia 44.51 [8]. This indicates that Indonesian students, particularly in the Bandung district, have some difficulties with this problem. 
Andini classified four categories of the difficulties experienced by elementary students in solving ratios and proportional relationships problems, such as (1) difficulty understanding the problem given, including unable to understand the phrases or keywords in the problems, confused in determining the problem-solving strategies; (2) difficulty solving the problem due to the low ability to perform integer and fraction operations; (3) difficulty when applying the concept of comparison to solve the problem.; and (4) difficulty when working on problems that have a different context from what they had learned [5]. These difficulties may lead to another difficulties or misconception of other related concepts [9]. In other words, students at a higher level may still have these difficulties or perhaps other difficulties in solving ratios and proportional relationships problems.

To further investigate student difficulties in solving ratios and proportional relationships from the perspective of junior high school students, this research will describe students' difficulties in solving ratios and proportional relationships problems. We focus on the ratios and proportional relationships for students in grade 7th of junior high school in Indonesia.

\section{Methods}

This research is qualitative research using the descriptive method to described students' difficulties in solving ratios and proportional relationships problems. This is in line with the purpose of descriptive research to describe a phenomenon and its characteristics [10] The descriptive methods in this study included three stages. First, we designed three problems on ratios and proportional relationships. Those problems were presented in Table 1. Those problems were adopted and adapted from the Indonesian National Exam and the students' textbook. Second, we tested the problem on ten students of junior high school grade 8 (14-15years old), and we interviewed the students about their solutions for the problem given. The interview was recorded so that all student answers could be recorded in detail. Finally, we analysed student answer papers and the results of the interviews that had been conducted to classify students' difficulties in solving ratios and proportional relationships problems.

Table 1. Design ratios and proportional relationships problems.

\begin{tabular}{cl}
\hline No. & \multicolumn{1}{c}{ Problem } \\
\hline 1 & If we know the value of $A=\frac{2}{3} I$ and $I=\frac{2}{5} R$. Then find the ratio of \\
& $A, I$, and $R !$ \\
2 & A car moves 120 kilometers within 2 hours, while a bike moves 100 \\
meters in 2 minutes. Determine the ratio of a car and bike speed! \\
3 A contractor can complete a job within 40 days with 15 workers. If \\
every worker has the same skill, determine how many additional \\
workers must finish a job in 30 days? \\
Mrs. Widi works in a training facility with a salary of 2 hours is Rp. \\
63.000. Determine the time of training by Mrs. Widi if she gets a salary \\
of Rp. 283.500?
\end{tabular}




\section{Results and Discussion}

Based on written test and interview analysis, we identified three common types of difficulties displayed by the students, such as (1) difficulty in ratios and proportional relationships word problems, (2) difficulty in applying arithmetic operations, and (3) difficulty in understanding the concept of ratios and proportional relationships. It reveals that the difficulty in understanding the concept of ratios and proportional relationships was the most frequent category, following by difficulty in applying arithmetic operations and the difficulty in ratios and proportional relationships word problems.

\subsection{Difficulty in ratios and proportional relationships word problems}

The difficulty in ratios and proportional relationships word problems refers to students' inability to understand the meaning of contextual word problems in ratios and proportional relationships topics. This difficulty included: students did not understand the problem given, mistranslated words or phrases into mathematical notations or formulas, and mistakes in choosing a plan to solve the problems. This difficulty is mainly seen in students' answers to problems number 3, 4, 1, and 2. Examples of student responses relevant to this category of difficulty can be seen in Figure 1(a) and Figure 1(b).

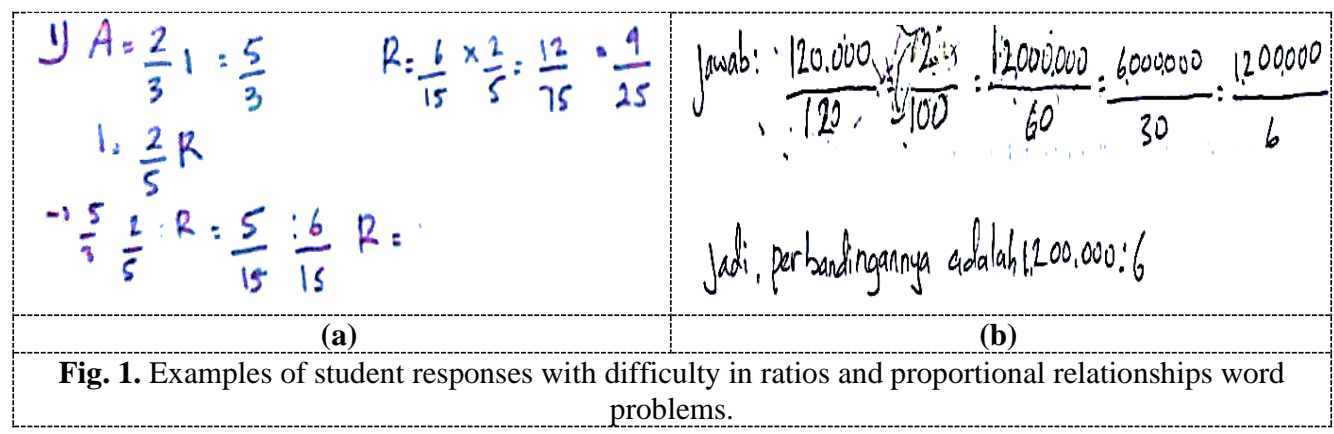

Figure 1(a) is an answer paper of a student S5 while trying to solve problem number 1 . We can see that S5 did not understand the problem given; S5 could not write what is known and what is asked in the problem. When the interview was conducted, S5 said that the known is a whole question 1 (re-read problem number 1). S5 did not get partially what is known and what is asked in the problems. For problem number 1, S5 was asked about the meaning of $A=\frac{2}{3} I$ and answered "A is two-thirds, and one" S5 read " $I$ " as a number (one). S5 mistranslated mathematical notation into numbers, resulting in a non-ratios and proportional relationships relation but a mixed fraction. This difficulty could occur because the students never use the format of ratios such as this problem, and students could not differentiate fractions as a ratio language. This finding is in line with the findings of studies performed by Irfan et al., where students did not understand the difference in ratio, fractional, and division [11].

Figure 1(b) is an answer paper of a student S10 while trying to solve problem number 2 . Understanding the unknown in the problem will determine what will be done in the final stage [12]. This reflects S10 answer; S10 did not understand what is unknown or what is asked from the problem can make a mistake in determining a plan to solve the problem. S10 made a mistake in deciding the formula used to solve the problem. Problem number 2 asks students to compare 
travel speeds by car and bicycle. It required students to use the formula of speed (distance divided by time) to obtain the relationship between two ratios (proportion). However, S10 compared the distance travel by car and the distance travel by bicycle, then combined it with a comparison of the time by car and bicycle.

Another effect of this difficulty is that students did not answer the questions thoroughly. There are missing steps conducted by the students. Student S9 had this difficulty in trying to solve problem number 3. Question number 3 is how many additional workers are required, but S5 answered only up to the workers' total number. S5 missed one step, where S5 needed to reduce workers' total number from the last number of workers.

\subsection{Difficulty in applying arithmetic operations}

Difficulty in applying arithmetic operations refers to students' mistakes and misconceptions about arithmetic operations (prerequisite material). This difficulty included: student make a mistake while doing addition, subtraction, multiplication, or division operations, student did not comply with the rules of the arithmetical operation order, student misapplied a commutative and associative property in calculation a division operation, student misapplied an additive or multiplicative inverse, and student misapplied cross-multiplication procedure. Examples of student responses relevant to this category of difficulty can be seen in Figure 2(a). and Figure 2(b).

\begin{tabular}{|c|c|}
\hline 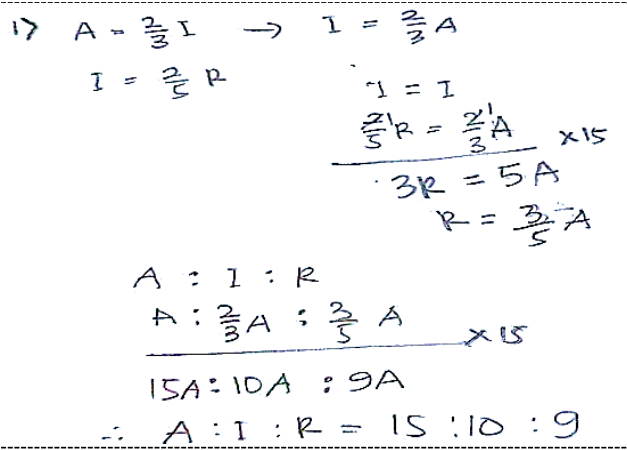 & $\begin{array}{l}3 \text { dik: harl: } 10 \text { hari dit: pekerja..? } \\
\begin{aligned} \text { Pekerja: } 15 & \text { jawab: } \\
\text { har12: } 30 \text { hari } \quad \frac{40}{30}: \frac{15}{a} \rightarrow k & \\
30 \div 15 & =3 \\
3 \times 40 & =120 \\
120-70 & =50\end{aligned}\end{array}$ \\
\hline (a) & (b) \\
\hline
\end{tabular}

Figure 2(a) is an answer paper of a student S8 while trying to solve problem number 1 . We could see that $\mathrm{S} 8$ misapplied multiplication inverse in changing $A=\frac{2}{3} I$ to $I=\frac{2}{3} A$ ( supposedly $I=\frac{3}{2} A$ ) and changing $3 R=5 A$ to $R=\frac{3}{5} A$ (supposedly $R=\frac{5}{3} A$ ). One possible causes is that $\mathrm{S} 8$ did not master enough division operations infractions (multiplication inverse infraction), which is the prerequisite material of ratios and proportional relationships topics. When interviews were conducted, S8 asks to divide two by $\frac{2}{3}$, but S8 answer is $2 \div \frac{2}{3}=\frac{2 \times 2}{3}=$ $\frac{4}{3}$. S8 did not understand there are different procedures of multiplication and division operations infractions. Students lack understanding of prerequisite material of fractions. This finding is in line with Daugherty's opinion that state misconceptions related to ratios and proportional reasoning depend on prerequisite knowledge of multiplication and fraction [3]. 
Figure 2(b) is an answer paper of a student S7 while trying to solve problem number 3 . We can see that S7 is trying to use the cross-multiplication procedure, but S7 confuses the step and what operation can be used in that procedure. There are missing steps in the S7 answer. First, S7 needs to change the proportion from $\frac{40}{30}=\frac{15}{a}$ to $40 \times a=30 \times 15$. Then uses multiplication inverse S7 can obtain $a=\frac{30 \times 15}{40}=\frac{450}{40}=11,25$. But this answer is still wrong because of the incorrect proportion made by S7. S7 had another difficulty in solving these problems, such as difficulties in understanding the ratios and proportional relationships concept that will discuss in the next section.

\subsection{Difficulty in understanding the concept of ratios and proportional relationships}

Difficulty in understanding the concept of ratios and proportional relationships refers to students' inability to use the different ratio formats, not compare two measure of the same types of things, confused about the concept of ratios with fractions and division operation, cannot simplify the ratio form to its simplest form, and student cannot differentiate between the concept of direct proportion and inverse proportion. Some students could not use a different format of ratios in solving problem number 1 , and they could not write the ratio of three quantities $(A: I: R)$, so they did not solve the problem entirely or did not solve the problem. Examples of student responses relevant to this category of difficulty can be seen in Figure 2(b) and Figure 3.

In Figure 2(b), student S7 made a mistake using the formula of inverse proportion. From the interview conducted, S7 cannot distinguish between the concept of direct proportion and inverse proportion. S7 did not remember there another formula to solve inverse proportion problems. This finding is in line with the research results that Diba conducted that students were not properly knowledgeable about the problem of direct and inverse proportions [13].

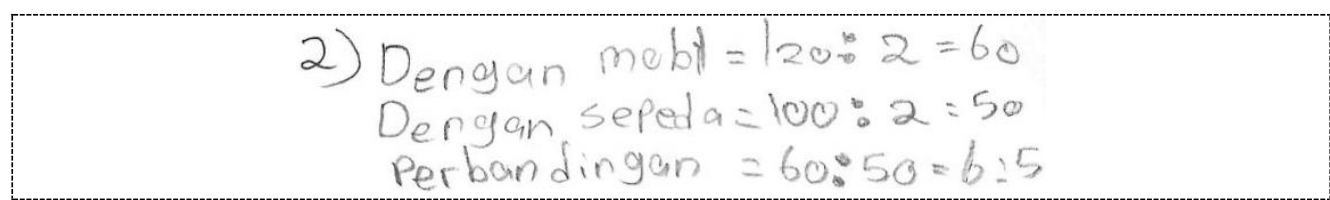

Fig. 3. Example of student responses with difficulty in understanding the concept of ratios and proportional relationships

Figure 3 is an answer paper of a student S3 while trying to solve problem number 2. Problem number 2 requires students to comparing two ratios (proportion), the travel speed of the car in kilometers per minute and the travel speed of a bicycle in meters per second. When comparing two ratios (proportion), two requirements need to follow. One of the requirements is comparing two quantities with the same types of measure [3]. However, S3 did not follow those requirements. S3 did not change the type of measure as one of the ratios, so the obtained answer is wrong. It implies that students lack an understanding of ratios and proportional relationships concepts. 


\section{Conclusion}

Many of the difficulties experienced by students emerge in question number 1. Students need to determine the ratio of three quantities and question number 3 , which students need to use the concept of inverse proportion to find the additional workers to be hired. Based on these findings, it can be concluded there are three common types of students' difficulties in solving ratios and proportional relationships problems, such as (1) difficulty in ratios and proportional relationships word problems, (2) difficulty in applying arithmetic operations, and (3) difficulty in understanding the concept of ratios and proportional relationships. The cause of these difficulties is due to students' lack of basic knowledge about prerequisite material, such as in the concept of fraction and arithmetic operations procedures, students' lack of comprehension when solving word problems with proportional ratio and relationship, and students' lack of conceptual understanding of ratios and proportional relationships topics. Therefore, it would be better to do further research on the causes of students' difficulties in solving ratios and proportional relationships problems to enhance students' comprehension in various classes or schools.

Acknowledgments. We would like to thank Prof. Turmudi, M.Ed., M.Sc., Ph.D. for his constructive comments and suggestions. We also thank the teachers and students for their participation.

\section{References}

[1] Muttaqin H, Putri RII, Somakin. Design research on ratios and proportional relationships learning by using ratio table and graph with Oku Timur content at the 7th-grade. J Math Educ 2017;8:21122. https://doi.org/http://dx.doi.org/10.22342/jme.8.2.3969.211-222.

[2] CCSSI. Common Core State Standards for Mathematics. Common Core State Stand Initiat 2010

[3] Dougherty B, Bryant DP, Bryant BR, Shin M. Helping Students With Mathematics Difficulties Understand Ratios and Proportions. Teach Except Child 2016;49. https://doi.org/10.1177/0040059916674897.

[4] Ben-Chaim, David, Keret, Yaffa, Ilany, Bat-Sheva. Ratio and Proportion. The Netherlands: Springer Science \& Business Media; 2012.

[5] Andini W, Jupri A. Student Obstacles in Ratio and Proportion Learning. J. Phys. Conf. Ser., vol. 812, 2017. https://doi.org/10.1088/1742-6596/812/1/012048.

[6] Kusuma NF, Subanti S, Usodo B. High-capability students' difficulties in problem solving on the concept of ratio. IOP Conf. Ser. Mater. Sci. Eng., vol. 296, 2018. https://doi.org/10.1088/1757899X/296/1/012021.

[7] TIMSS. Timss 2011 International Results in Mathematics. 2012.

[8] Pusat Penilaian Pendidikan Kementrian Pendidikan dan Kebudayaan. Laporan Hasil Ujian Nasional 2018. https://hasilun.puspendik.kemdikbud.go.id (accessed December 24, 2020).

[9] Bambico T. Mathematical Strengths, Difficulties and Misconceptions of Teachers : Analysis of Their Performance in an Achievement Test 【Article】. Math Strengths, Difficulties Misconceptions Teach Anal Their Perform an Achiev Test 【Article】 2002;9:41-60. https://doi.org/10.15027/14389.

[10] Nassaji H. Qualitative and descriptive research: Data type versus data analysis. Lang Teach Res 2015;19:129-32. https://doi.org/10.1177/1362168815572747.

[11] Irfan M, Nusantara T. Why Did the Students Make Mistakes in Solving Direct and Inverse Proportion Problem? Int J Insights Math Teach 2018;1.

[12] Hayyulbathin I, Winarni R, Murwaningsih T. Modification of Polya's Step to Solve Math Story 
Problem. 5th ICRIEMS Proc., 2018, p. 119-26.

[13] Diba DMS, Prabawanto S. The analysis of students' answers in solving ratio and proportion problems. J. Phys. Conf. Ser., vol. 1157, 2019. https://doi.org/10.1088/1742-6596/1157/3/032114. 